Rev. Latinoam. Psicopat. Fund., III, 4, 165-171

Vastas confusões e atendimentos imperfeitos: a clínica psicanalítica no ambulatório público

Ana Cristina Figueiredo

Rio de Janeiro, Relume-Dumará, 2ª ed., 2000

\title{
Vastas confusões e atendimentos imperfeitos
}

Fernando Tenório

Numa pequena cidade, um peão campeiro chega a cavalo no serviço de saúde e diz à psicóloga: "Eu tenho uma coisa que remédio não cura... meu passado está voltando”. Num grupo de recepção e triagem de um ambulatório psiquiátrico, uma mulher grita, em crescente desespero, ao falar de sua compulsão à limpeza: "eu preciso de alguém que me diga assim: chega, pára”. O profissional responde ao pé da letra: “então pára!”, e esta intervenção abre a chance de um encaminhamento para análise. Em um ambulatório público de saúde mental, uma terapeuta de família é chamada a fazer um atendimento familiar de um paciente psicótico, recémsaído de uma internação. Começa a atender o paciente junto com seu pai, sua mãe e seu irmão. Paranóico, o paciente acreditava que "os homossexuais" iam "tomar o sítio" da família. Depois de um tempo, o atendimento passa a ser separado: os pais numa sessão e os irmãos em outra. Como efeito do tratamento, o paranóico passa a duvidar da perseguição e o neurótico diz que está aprendendo com o irmão a pensar na vida. Sem pretensão de "fazer análise”, a terapeu- 
ta fez função de um terceiro que permitiu uma elaboração, fez função de analista. Isto se deixa ver quando o paranóico, não obstante morar com os pais, pede que eles venham a uma sessão para que ele possa saber como eles estão. O irmão neurótico corrobora a suposição de saber ao concordar com o pedido.

Estes e outros fragmentos foram colhidos por Ana Cristina Figueiredo em sua pesquisa de campo sobre a clínica psicanalítica no ambulatório público, e estão relatados e discutidos no livro Vastas confusões e atendimentos imperfeitos, agora lançado em segunda edição. A primeira edição, de 1997, rapidamente tornou-se referência no campo da assistência em saúde mental no Rio de Janeiro. Ana Cristina trabalha, há muitos anos, como professora e supervisora clínica no Instituto de Psiquiatria da UFRJ, onde é coordenadora do Curso de Especialização em Clínica Psicanalítica em Instituição. Seu livro, mais do que uma pesquisa de doutoramento, é tanto resultado quanto continuação desse lugar e desse trabalho: lugar de dedicação à causa psicanalítica, de um evidente compromisso com a coisa pública e de um amor pela universidade declarado já na dedicatória da tese. Este percurso capacita e autoriza Ana Cristina a ter uma relação singular com a ortodoxia psicanalítica, por um lado, e com a estreita resistência à psicanálise, por outro, produzindo uma obra singular.

Provocativo, o título pode dar a entender que a psicanálise praticada nos ambulatórios públicos é "imperfeita” e "confusa” no sentido de inferior, pior, aquém da "verdadeira psicanálise" que se faz no consultório privado. Nada mais distante da verdade: toda a força do trabalho da autora está na demonstração de que não há duas psicanálises, a "pura” (do consultório) e a “impura” (dos ambulatórios). O que há são condições mínimas para que se possa reconhecer como psicanalítico um certo trabalho clínico, seja no consultório, seja nos ambulatórios. Pela riqueza dos depoimentos colhidos em sua pesquisa e pela mestria com que os articula às proposições de Freud e Lacan, a autora propõe quais são essas "condições mínimas” e demonstra que elas são possíveis no ambulatório, sendo alcançadas por meio do trabalho efetivo do psicanalista, e não das garantias imaginárias dadas pelo consultório ou pela identidade de "psicanalista".

O objetivo da autora é, como ela própria diz, prescritivo. De fato, tendo se lançado à pesquisa com o objetivo de "ampliar o leque de informações sobre as possibilidades e limites do exercício da psicanálise fora dos consultórios privados”, ela acaba por prescrever "um modo de conceber a especificidade da psicanálise e da função do psicanalista" que vale não apenas para o ambulatório, mas para toda e qualquer psicanálise. Afinal, não há duas psicanálises.

O livro tem três capítulos. O primeiro - "O que é feito da psicanálise" - parte dos problemas colocados pela difusão da psicanálise e discute a própria definição de psicanálise como problemática, dada a heterogeneidade do campo. Após revisar os três modelos pregnantes do campo psicanalítico (o de Melanie Klein, a psicolo- 
gia do ego e o movimento constituído a partir de Lacan), a autora recusa qualquer "solução eclética” que transforme a psicanálise numa colagem sem consistência. Propõe, com Bercherie, que cabe a cada analista ultrapassar sua filiação para reinventar a psicanálise. Mantém-se, porém, o problema de como fazê-lo sem romper com o que caracteriza e delimita a psicanálise. Ainda neste capítulo, é discutida a questão do ambulatório como um novo contexto para a psicanálise. Todos os objetos, diz Rorty, já são contextualizados, não havendo um objeto em si que antecede o contexto. O ambulatório, então, é um "novo contexto", que implica uma nova psicanálise? A dificuldade é semelhante àquela enfrentada para a definição de psicanálise: se a psicanálise é recontextualizada, seja em uma revisão conceitual, seja em uma relocalização de sua prática clínica, “o que garante que novas recontextualizações, ao produzirem novos objetos, não nos lançariam no paradoxo de não estarmos mais falando de psicanálise?”. Para “estancar a dúvida”, Ana Cristina recorre ao conceito de réstance, de Derrida, como aquilo que resiste à transformação operada pelo contexto e que permite o reconhecimento do antigo signo. "A dicotomia consultório privado versus ambulatório público não pode ser tratada como confronto entre dois contextos, radicalmente diferentes, que supõem duas psicanálises, pois estaríamos tomando o local e suas condições como o contexto por excelência, o que é, no mínimo, uma diferença grosseira, senão uma falsa questão”. Não há duas psicanálises, nunca é demais lembrar, mas a autora parte taticamente dessa dicotomia para, em sua pesquisa, explorar as possibilidades do exercício da clínica psicanalítica.

A pesquisa de campo é apresentada no segundo capítulo - "Interrogando o ambulatório”. Ana Cristina entrevistou 28 profissionais da rede pública, entre psiquiatras, psicólogos e psicanalistas, que atuam em ambulatórios, centros e postos de saúde, hospitais psiquiátricos e não-psiquiátricos. A isso juntou sua observação direta como supervisora e docente do Instituto de Psiquiatria da UFRJ, bem como o material obtido no grupo de discussão que coordenou no Círculo Psicanalítico do Rio de Janeiro sobre o tema em questão.

Nada substitui a leitura do capítulo. Privilegiando o discurso direto dos entrevistados, a autora construiu um registro instrutivo, divertido e emocionante do trabalho daqueles que se dedicam a, como diz Freud, levar a psicanálise “... ao grande número de pessoas que não sofrem menos de neurose que os ricos mas não estão em condições de pagar os custos de seu tratamento" ("Prólogo a Zehn Jahre Berliner Psychoanalytisches Institut”, Obras completas, vol. XVII). Alguns relatos revelam total incompreensão do que seja uma intervenção analítica: por exemplo, o de um profissional que afirma que a clientela dos ambulatórios não entende uma "interpretação mais profunda" e dá como exemplo uma senhora que, reclamando de ter de cuidar do marido alcoólatra, "não queria acreditar” na interpretação de que isto se relacionava ao fato dela não ter amamentado seu filho. Pode-se per- 
guntar: como é possível que uma intervenção desta natureza, pedagógica, tenha efeito de interpretação no sentido analítico (de um dizer que causa alguma coisa, mais do que revela a suposta causa), qualquer que seja a clientela? No entanto, predominam os relatos de intervenções que, como aquelas citadas acima, fazem valer, em contextos os mais diversos, uma clínica do sujeito. Os casos e fragmentos são tomados como exemplares no duplo sentido de amostra e paradigma. Por meio deles, a autora discute o funcionamento dos serviços e a atuação dos profissionais naquilo que podem facilitar ou dificultar um trabalho psicanalítico: os mecanismos de recepção, triagem e encaminhamento; as diversas modalidades de atendimento no campo da assistência; as vicissitudes do trabalho em equipe multiprofissional; os sintomas, encontros e desencontros de psiquiatras, psicólogos e psicanalistas. A última parte do capítulo trata dos três aspectos que ocupam o centro das objeções à prática da psicanálise no ambulatório: dinheiro, divã e tempo. A impossibilidade de cobrar dinheiro no serviço público exige do analista estar atento a que tipo de pagamento é possível aí (ou, como diz a autora noutro trecho, "localizar como o sujeito paga por estar lá”). A ausência do divã como barreira à pregnância do olhar na transferência não impede que outro manejo possa apagar a figura imaginarizada do analista e fazer de sua presença um operador da fala. E se a burocracia ou a peculiaridade da clientela impõem complicações à freqüência das sessões e à duração do tratamento, a autora traz alguns exemplos de manejo clínico da função singular do tempo no trabalho analítico.

No terceiro capítulo - "Por uma psicanálise possível” -, Ana Cristina recorre à metapsicologia freudiana e à leitura de Lacan para propor "as condições mínimas para que se identifique como psicanálise determinado modo de trabalho clínico”.

A primeira condição é a de que a psicanálise é uma clínica da fala, que diz respeito à realidade psíquica, não como realidade menor mas, ao contrário, como a "única realidade que diz respeito e interessa ao sujeito, a partir da qual ele se vê, pensa, fala, sofre, trabalha...”. Muito tempo passará, dizia Freud em 1917, “até que se possa aceitar nossa proposta de igualar fantasia e realidade" (citado pela autora). Segunda condição: trata-se de produzir um modo de fala por meio da transferência. De uma fala que é desabafo, queixa ou pedido de ajuda endereçado a alguém que supostamente sabe sobre o sofrimento e a cura, deve-se levar o sujeito a ser afetado pelo que diz, formulando uma questão. Esta passagem depende da ação do analista, com o que se chega à terceira condição: a interpretação, entendida na perspectiva de uma temporalidade específica, a do Nachträglichkeit, ou só-depois. A interpretação não visa descobrir ou revelar a causa, no sentido do porquê, mas sim causar um efeito - o que só se sabe depois. Neste sentido, a ação do analista "só tem valor de interpretação, como efeito, num tempo posterior". A elaboração como trabalho analítico não é, portanto, nem a revelação de uma influência do passado sobre o presente, nem uma regressão ao passado da infância. A análise 
visa à construção de algo (que chamamos fantasia) que, uma vez construído, será tomado pelo sujeito como aquilo que desde sempre selou seu destino, terá sido o que determinou desde sempre este destino. Simplificando, o trabalho analítico visa possibilitar ao sujeito "mudar sua posição em relação à fantasia que sustenta seu sintoma”, passando de um "destino selado" para um "destino em aberto" - ainda que algo sempre reste, marcando este destino.

Há, ainda, uma última e decisiva condição: o analista. O que faz um analista? (isto é, qual é sua ação?). O que faz de alguém um analista? (isto é, como alguém se torna analista?). O que quer um analista? (de seu trabalho, de uma análise, de seu paciente). Como se vê, a última das “condições mínimas” da psicanálise envolve tanto um percurso quanto uma posição do analista. "O caminho que o analista deve seguir (...) é um para o qual não existe modelo na vida real”, diz Freud em Observações sobre o amor de transferência (citado pela autora). Com Lacan, Ana Cristina nomeia esta condição em termos do desejo do analista. O desejo do analista, a autora cita Lacan, é “desejo de obter a diferença absoluta”. A contribuição decisiva de Lacan, aqui, está em formalizar que não há dois desejos, ou dois sujeitos, na análise. O desejo do analista não é desejo de sujeito; o analista como "sujeito suposto saber" é um operador da análise como suposto, e na referência ao saber. A suposição, da parte do analisante, faz operar uma fala endereçada ao analista e esta fala é, de início, o pedido de um saber. Se o amor é a ilusão de que o amado detém o objeto que pode suprir a falta do sujeito, no amor de transferência o que o analista é suposto ter é um saber sobre a cura, ou sobre o inconsciente. A diferença que caracteriza a posição do analista está em, aparecendo para o sujeito como o objeto de seu desejo, não se colar a esta condição em que o analisante o coloca. Ao contrário, trata-se de remeter ao objeto que falta e que causa o desejo. Este é o sentido da proposição lacaniana de que o analista deve fazer semblante do objeto causa de desejo, ou "objeto a”. Diz a autora: “... o analista se subtrai para causar desejo como efeito desta subtração. (...) Só assim o analista pode remeter o sujeito adiante no caminho de sua fala (...) remetendo a novas significações que, por sua vez, se desfazem, afetando o sujeito, provocando viradas, causando desejo”.

Para concluir, Ana Cristina indica o caminho para os analistas dispostos a enfrentar com sucesso a aventura de praticar a psicanálise fora do consultório privado. O psicanalista que convém a essa aventura, diz ela, não é o que convence, nem o que vence, nem o convencido, nem o que usa a docilidade para esconder sua arrogância. $\mathrm{O}$ psicanalista que convém é o que convive. $\mathrm{O}$ analista deve ter clareza de seus propósitos e de seu ofício, para sustentar uma oferta ou uma possibilidade de análise em meio a circunstâncias que podem ser mais ou menos favoráveis ao trabalho psicanalítico. Deve ser capaz de, a partir dos diferentes dispositivos de tratamento (como hospitais gerais, hospitais psiquiátricos, hospitais-dia, centros de atenção psicossocial...), e neles mesmos, sustentar uma escuta analítica, cujo efei- 
to pode ser o início de uma análise, mas que não precisa chegar a isso para se justificar clinicamente como uma contribuição específica da psicanálise. O psicanalista que se julga "especial”, no sentido de melhor que os outros especialistas, costuma aumentar as resistências à psicanálise e obstruir a circulação da palavra, dificultando a discussão clínica nas equipes multiprofissionais e muitas vezes o próprio trabalho clínico. Já o psicanalista que, sem deixar de estar ciente da especificidade do trabalho psicanalítico, faz da clínica a via de uma conversa que respeita a especificidade de outros profissionais, não apenas favorece o seu trabalho em particular como pode levar mais além a contribuição da psicanálise. O desejo do analista como "desejo de diferença absoluta" não pode ser entendido, alerta a autora, pela via do "narcisismo das pequenas diferenças". Não se trata de "ser diferente de", mas de produzir diferença. No que diz respeito ao nosso narcisismo, trata-se de "suportar essa designação de psicanalista sem que isso diga algo de consistente sobre seu [nosso] ofício".

O livro de Ana Cristina Figueiredo é, claramente, um trabalho escrito para ensinar, ser útil, contribuir para a formação daqueles que se propõem a um trabalho clínico na rede pública referido à psicanálise. Claramente, visa aqueles que, com reconhecimento maior ou menor da corporação analítica, enfrentam o desafio de praticar a clínica psicanalítica em condições muitas vezes desfavoráveis. Não por acaso, em meio a um mapeamento nada condescendente que Ana Cristina faz dos sintomas de psiquiatras, psicólogos e psicanalistas, encontramos um elogio, quase uma homenagem, àqueles que podemos chamar, em sentido amplo, de seus alunos:

... mesmo não se apresentando como psicanalistas, falam com simplicidade de uma clínica onde vêem acontecer situações de análise muito próximas das encontradas no consultório. De um modo geral, parecem ainda não ter conseguido em seu percurso um reconhecimento ou autorização para se dizerem psicanalistas. (...) Por este mesmo motivo, buscam supervisões, conversam com colegas, recorrem aos livros, grupos de estudo e às suas próprias análises. Curiosamente, eles põem em marcha a concepção de formação analítica por excelência proposta por Freud e sistematizada, nem sempre da melhor maneira, nas sociedades psicanalíticas.

Retoma-se, com este trabalho, uma discussão até certo ponto antiga na psicanálise brasileira, antes designada pela expressão "psicanálise e população de baixa renda”. Porém, Ana Cristina faz a discussão aceder a um outro patamar. Primeiro, porque seu estudo não trata especificamente da adequação da psicanálise a uma certa clientela, cobrindo mais exaustivamente o conjunto de variáveis que envolvem a prática psicanalítica na assistência pública em saúde. Segundo, e mais importante, porque, sem deixar de considerar as especificidades do contexto, traz a discussão para os termos rigorosamente psicanalíticos. Um trabalho que vai do 
ambulatório para a psicanálise. Impedida de esconder-se no indevassável do consultório, interpelada pelas condições adversas do ambulatório, a psicanálise é forçada a fundamentar com mais rigor sua prática, sua direção.

Acrescentemos, nesta perspectiva, dois elementos à discussão: 1) o setting do consultório pode permitir ao analista economizar-se do trabalho de manejar aquilo que as "condições adversas" do ambulatório trazem à cena (por exemplo: o pagamento burocrático de uma quantia de dinheiro pode economizar o analista do trabalho de localizar como o analisante paga por estar ali; a disponibilidade infinita de uma clientela "aculturada” pode se traduzir na aceitação de uma análise que não termina, não provoca efeitos etc.); 2) o caráter privado do consultório pode eximir os analistas de submeter seu trabalho à apreciação dos colegas (salvo que façam isto em suas instituições psicanalíticas, o que nem sempre acontece).

O exercício extramuros da psicanálise convoca o analista a responder clínica e teoricamente àquilo que a privacidade ou a regularidade do consultório permitem elidir. Neste sentido, não estaria o ambulatório mais próximo do espírito do trabalho analítico tal como preconizado por Freud e Lacan? Não se trata, obviamente, de inverter os termos da equação e afirmar, agora, que só se faz psicanálise no ambulatório. Trata-se, antes, de enfatizar o caráter público de uma psicanálise que se faz em meio à diversidade, aos desafios clínicos de toda ordem e à necessidade de prestar contas (clinicamente) de seu trabalho.

Na Ata de Fundação da Escola Freudiana de Paris, Lacan estabelece que o trabalho ali realizado será submetido a um controle "interno e externo". Anos depois, na Abertura da Seção Clínica daquela instituição, Lacan sustenta que ali se visa convidar o analista a que “declare suas razões”. Sem a ingenuidade de afirmar que o ambulatório garante a formação de analistas ou substitui a instituição psicanalítica, devemos extrair todas as conseqüências da seguinte proposta de Ana Cristina: o ambulatório, diz ela, é o consultório tornado público. Ora, não seria o espaço público o lugar por excelência da psicanálise? 